\title{
Albumin nanoparticles loaded with hemin as peroxidase mimics for immunoassay
}

Pavel Khramtsov ${ }^{1,2 *}$, Maria Bochkova ${ }^{2}$, Valeria Timganova ${ }^{2}$, Dmitriy Kiselkov³, Svetlana Zamorina ${ }^{1,2}$, Mikhail Rayev ${ }^{1,2}$

${ }^{1}$ Perm Federal Research Center of the Ural Branch of The Russian Academy of Sciences, Lab of Ecological Immunology, Institute of Ecology and Genetics of Microorganisms, 614081, 13 Golev str., Perm, Russia;

${ }^{2}$ Department of Biology, Perm State University, 614068, 15 Bukirev str., Perm, Russia

${ }^{3}$ Perm Federal Research Center of the Ural Branch of The Russian Academy of Sciences, Institute of Technical Chemistry, 614013, 3 Academician Korolev str., Perm, Russia

\begin{abstract}
Contemporary immunoassays commonly used in clinical diagnostics mostly utilize enzymes, such as horseradish peroxidase, for signal generation. Numerous research is dedicated to the development of artificial peroxidase-mimicking catalysts with lower cost, high activity, better operational stability, and tunable properties. Herein we synthesized hemin-loaded bovine serum albumin (BSA) nanoparticles and applied them as catalytic labels (nanozymes) in colorimetric immunoassay of anti-tetanus antibodies. Hemin is a key part of the peroxidase catalytic center, possessing peroxidase like-activity. Albumin nanoparticles were loaded with multiple hemin molecules and decorated with Streptococcal protein G. Resulting nanozymes possessed good colloidal stability and allowed for antibody detection in blood serum. The sensitivity of antibody detection was sufficient for the assessment of post-vaccination immunity.
\end{abstract}

\section{Keywords}

Antibody, ELISA, enzyme catalysis, immunization, nanoparticles, nanozyme.

\section{Introduction}

In the field of biosensing, much effort is currently made to develop artificial structures mimicking the catalytic activity of natural enzymes like peroxidases, oxidases, proteinases, and so on [Huang, 2019]. These researches stem from the idea of obtaining artificial constructs with higher stability, lower cost, and tunable properties which can substitute enzymes providing more opportunities to sensors and assays manufacturers [Das, 2021]. Traditionally, clinical diagnostics relies mostly on enzyme-linked immunosorbent assay (ELISA) when detection of hormones, tumor markers, or antibodies against pathogens is required [Aydin, 2015]. ELISA is a well-established technique whose principle is binding of an analyte by recognition molecule (usually monoclonal antibody) covalently conjugated with an enzyme. The role of the enzyme is to generate a color signal by transforming an uncolored substrate into a colored product. Measurement of color intensity allows for the quantification of an analyte. Horseradish peroxidase along with alkaline phosphatase are the two most popular enzymes utilized in commercial ELISAs. A plethora of horseradish peroxidase mimics has been reported so far, with most of them belonging to 2D and 3D nanomaterials. Since 2007 when Gao et al. demonstrated peroxidase activity of Fe3O4 nanoparticles [Gao, 2007], various metal-based nanoparticles were also shown to possess enzyme-like activity as well as graphene-like nanoparticles, metal-organic frameworks, single-atom nanozymes, and so on [Shen, 2020]. 
The idea of the present study is to synthesize hemin-loaded albumin nanoparticles by desolvation technique and use them as peroxidase-mimicking labels in colorimetric immunoassay. Hemin being a core element of horseradish peroxidase catalytic site possesses significant peroxidase-like activity. Despite horseradish peroxidase having much higher molar-weighted catalytic activity, the weight-normalized catalytic activity of hemin exceeds that of horseradish peroxidase [Zhang, 1992]. In principle, hemin was already successfully used as a peroxidase substitute in the mid-80s. Ikaryama et al. developed chemiluminescence immunoassays harnessing hemin-tagged proteins with the limit of detection as low as $1 \mathrm{ng} / \mathrm{ml}$ [Ikariyama, 1982, Ikariyama, 1984]. We suggested that higher sensitivity can be reached by labeling recognition molecules with hemin-enriched nanoparticles.

Albumin nanoparticles can potentially provide delivery of multiple hemin molecules per one analyte molecule to outperform peroxidase-based assay. Albumin/hemin complexes with peroxidatic activity are normally found in human blood and play a crucial role in the pathogenesis of hematologic diseases [De Simone, 2021]. In 2016 Dong et al. reported that covalent and noncovalent assemblies of albumin and hemin had respectively 4- and 2-fold higher catalytic activity compared to intact hemin [Dong, 2016]. These results contradicted previous studies showing that albumin markedly decreases the peroxidase- and catalase-like activity of heme [Grinberg, 1999], however, the idea to use albuminlhemin complexes for biosensing properties was appealing because albumin could potentially improve the solubility of hemin at neutral $\mathrm{pH}$ and provide functional groups for subsequent conjugation. Unfortunately, according to Dong et al. [Dong, 2016] stability of noncovalent albumin/hemin complexes in aqueous solutions was poor. In turn, covalent attachment of hemin is a more complex and time-consuming process, which requires the purification of the product. We suggested that desolvation of non-covalent albumin/hemin complexes might be both an efficient and simple way to obtain peroxidase mimicking nanozymes. Desolvation stands out as a straightforward approach to protein nanoparticle preparation. This method relies on the addition of organic solvent which is able to mix with water (ethanol, methanol, acetone) to aqueous protein solution [Weber, 2000]. At a certain concentration of the organic solvent solubility of protein decreases followed by the formation of protein nanoparticles. Dissolution of nanoparticles is usually prevented by cross-linking with glutaraldehyde. Various labels such as fluorescent dyes [Zhang, 2013], nanoparticles [Zare, 2021], and enzymes [Lee, 2019] can be loaded into albumin nanoparticles, which is supported by the ability of albumin to form complexes with small organic molecules. There are multiple hemin binding sites in the albumin molecule [Beaven, 1974], therefore simple loading of hemin by direct mixing with protein is possible. Various functional groups across the nanoparticles' surface enable different routes of covalent coupling with recognition elements such as monoclonal antibodies. Good colloidal stability and relatively simple manufacturing are other attractive features of protein nanoparticles. Importantly, the desolvation method was recently applied to obtain hemin-loaded albumin nanoparticles [Yu, 2020]. These nanozymes were able to provide $\mathrm{H} 2 \mathrm{O} 2$ detection confirming that a desolvation is a promising approach to obtaining hemin-based nanozymes. However, the application of such nanoparticles in immunoassay was not reported.

The goals of this study included: 1) Preparation of hemin-loaded nanozymes with different albumin:hemin ratio; 2) Characterization of synthesized nanoparticles; 3) Application of the nanozymes in the colorimetric immunoassay of anti-tetanus antibodies.

\section{Experimental \\ Materials}


Bovine serum albumin (BSA) was from VWR (USA). Hemin, casein, fluorescein isothiocyanate (FITC), boric acid, tris(hydroxymethyl)aminomethane (TRIS), sodium dodecyl sulphate (SDS), Proclin-950, and human IgG were from Sigma-Aldrich (USA). Tween-20, (4-(2-hydroxyethyl)-1-piperazineethanesulfonic acid) (HEPES), 2-(Nmorpholino)ethanesulfonic acid (MES), glutaraldehyde, citric acid, oxalic acid, imidazole, glycine, sodium phosphate, sodium bicarbonate, and glycerol were from ITW (USA). Sodium hydroxide, sulphuric acid, and hydrochloric acid were from Reakhim (Russia). Recombinant protein G from Streptococcus sp. was kindly provided by Dr. Tatyana Gupalova, Institute of Experimental Medicine (St.-Petersburg, Russia). Tetanus toxoid was from Mikrogen (Russia). WHO standard of human anti-tetanus IgG (TE-3) was from NIBSC (UK). Reagents for gel electrophoresis were from Bio-Rad (USA). Pooled rabbit serum was from Biosera (France).

Immunoassay buffers. 0.2 M carbonate buffer, $\mathrm{pH}$ 9.6; phosphate buffer (PB, 0.15 $\mathrm{M} \mathrm{NaCl}, 0.015 \mathrm{M} \mathrm{Na}_{2} \mathrm{HPO}_{4}, 0.015 \mathrm{M} \mathrm{NaH}_{2} \mathrm{PO}_{4}$, and 0.05\% Proclin-950, pH 7.25) and PBT (PB+0.1\% Tween-20).

Substrate buffers: $0.1 \mathrm{M}$ citrate-phosphate buffer, $\mathrm{pH}$ 3-7; $0.1 \mathrm{M}$ acetate- $\mathrm{NaOH}$ buffer, $\mathrm{pH} 4$ and 5; $0.1 \mathrm{M}$ acetate- $\mathrm{NH}_{4} \mathrm{OH}$ buffer, $\mathrm{pH} 4$ and 5; $0.1 \mathrm{M}$ citrate- $\mathrm{NaOH}$ buffer, $\mathrm{pH}$ 3-7; $0.1 \mathrm{M}$ citrate- $\mathrm{NH}_{4} \mathrm{OH}$ buffer, $\mathrm{pH}$ 3-7; $0.1 \mathrm{M}$ oxalate-NaOH buffer, $\mathrm{pH} 4$ and 5; 0.1 $\mathrm{M}$ oxalate- $\mathrm{NH}_{4} \mathrm{OH}$ buffer, $\mathrm{pH} 4$ and 5; $0.1 \mathrm{M}$ glycine- $\mathrm{HCl}$ buffer, $\mathrm{pH} 2$ and 3; $0.1 \mathrm{M}$ glycine$\mathrm{NaOH}$ buffer, $\mathrm{pH} 9$ and 10; $0.1 \mathrm{M}$ TRIS-HCl buffer, $\mathrm{pH} 8$ and 9; $0.1 \mathrm{M}$ TRIS-glycine buffer, $\mathrm{pH} 8$ and 9; $0.1 \mathrm{M}$ HEPES-HCl buffer, $\mathrm{pH}$ 3, 7, and 8; $0.1 \mathrm{MES}-\mathrm{NaOH}$ buffer, $\mathrm{pH} 6$ and 7; $0.1 \mathrm{M}$ Na-phosphate buffer, $\mathrm{pH}$ 6-8; $0.1 \mathrm{M}$ imidazole-HCl buffer, $\mathrm{pH}$ 7; $0.1 \mathrm{M}$ TRIS-MES buffer, pH 6-8; $0.1 \mathrm{M} \mathrm{Na-carbonate} \mathrm{buffer,} \mathrm{pH} 10$ and 11; $0.1 \mathrm{M}$ Na-borate buffer, $\mathrm{pH} 9$ and 10.

The following instrumentation was used: Stat Fax 2600 Microplate Washer Awareness Technologies, (USA), ZetaSizer NanoZS particle analyzer, Malvern (UK), Protean Mini electrophoresis device, Bio-Rad (USA), Slide-A-Lyzer dialysis kit, Thermo (USA).

Synthesis of BSA nanoparticles loaded with hemin (BSA/hemin nanoparticles)

Hemin powder $(48,24,12,6$ or $3 \mathrm{mg})$ was added to $6 \mathrm{ml}$ of $40 \mathrm{mg} / \mathrm{ml}$ aqueous BSA solution. From 100 to $200 \mu \mathrm{l}$ (depending on the amount of hemin) of $1 \mathrm{M} \mathrm{NaOH}$ was added by small portions to the mixture of BSA and hemin until the disappearance of visible hemin lumps. After the addition of each alkali portion, the mixture was vigorously vortexed for 10-20 s. The $\mathrm{pH}$ of the resulting solution was between 10 and 10.5. Then, the $\mathrm{pH}$ of the solution was adjusted to 11 [Winterhalter, 1964] using the $\mathrm{pH}$ meter. The solution was kept on a rotator (360 degrees, $10 \mathrm{rpm}$ ) for $1 \mathrm{~h}$ at $+37^{\circ} \mathrm{C}$ and then sonicated (20 s, $18 \mathrm{~W}, 3 \mathrm{~mm}$ probe). Four milliliters of the resulting solution were transferred to a glass beaker and warmed to $+35^{\circ} \mathrm{C}$ with constant stirring on a magnetic stirrer (700 rpm). Ethanol (95\%) was added dropwise $(1 \mathrm{ml} / \mathrm{min})$ to the stirred solution with the aid of a peristaltic pump. After the addition of $5 \mathrm{ml}$ of ethanol, the pump was stopped, and a $1 \mathrm{ml}$ sample was taken from the reaction volume. The absorbance of this sample at 600 and $700 \mathrm{~nm}$ was measured in a quartz cuvette $(0.1 \mathrm{~cm}$ path length), then the sample was returned to the reaction vessel. Ethanol addition was resumed. After 1 min the sample was again taken and measured. This procedure was repeated until the growth of absorbance was not observed. The formed nanoparticles were allowed to cross-link for 2 hours at $+70{ }^{\circ} \mathrm{C}$ under stirring. After that, the suspension was cooled to RT, transferred into $2 \mathrm{ml}$ centrifuge tubes, and centrifuged at $20000 \mathrm{~g}$ for $60 \mathrm{~min}$. Supernatants were removed, then water was added to the nanoparticle pellet. Nanoparticles were redispersed by sonication ( $20 \mathrm{~s}, 10 \mathrm{~W}, 3 \mathrm{~mm}$ probe), then washed two more times, combined, and stored at $+4{ }^{\circ} \mathrm{C}$. 
Unloaded nanoparticles were prepared in the same way except that the BSA solution $\mathrm{pH}$ was 9.3, synthesis was performed right after the $\mathrm{pH}$ adjustment, and monitoring of absorbance was not performed. Ethanol was added until the solution became turbid.

The resulting nanoparticles will be further referred to as NP5 (48 $\mathrm{mg}$ of hemin + $160 \mathrm{mg} \mathrm{BSA}$; the mass ratio of BSA to hemin is 5:1), NP10 (24 mg of hemin, 10:1), NP20 (12 $\mathrm{mg}$ of hemin, 20:1), NP40 (6 mg of hemin, 40:1), NP80 (3 mg of hemin, 80:1), and NPC (unloaded nanoparticles).

\section{Characterization of nanoparticles}

Size (z-average hydrodynamic diameter), polydispersity, and zeta-potential of nanoparticles were assessed by the dynamic light scattering (DLS). For the size measurements, nanoparticles were diluted at 1:100 in the deionized water. For zeta potential measurements nanoparticles were diluted in a $10 \mathrm{mM}$ phosphate buffer, $\mathrm{pH} 7$ (ionic strength of 0.05). Measurements were performed in auto mode using a generalpurpose model. Ionic strength was adjusted with $1 \mathrm{M}$ KNO3. The measurements were done with three technical replicates.

Absorbance spectra of nanoparticles were measured at wavelengths between 200 and $900 \mathrm{~nm}$. Nanoparticles were diluted in deionized water to $50 \mu \mathrm{g} / \mathrm{ml}$ and transferred in a quartz cuvette (1 cm path length).

The concentration of nanoparticles was measured by gravimetric analysis. The sample of nanoparticle suspension $(1 \mathrm{ml})$ was added to the porcelain crucible and dried to constant weight at subsequently $+95^{\circ} \mathrm{C}$ and $+140{ }^{\circ} \mathrm{C}$. Both protein and hemin do not decompose at these temperatures [Zhu, 2018, Francisca Gómez-Rico, 2005].

The amount of hemin loaded into BSA nanoparticles was determined by spectrophotometry. Nanoparticle samples $(100 \mu \mathrm{l})$ were mixed with $900 \mu \mathrm{l}$ of $1 \%$ BSA solution in $1.1 \mathrm{M} \mathrm{NaOH}$. Hemin calibrators $(100 \mu \mathrm{l})$ were mixed with $900 \mu \mathrm{l}$ of $1 \% \mathrm{BSA}$ solution in $1 \mathrm{M} \mathrm{NaOH}$. Nanoparticles were analyzed undiluted and diluted 1:2 and 1:4 in water. Hemin was diluted in $1 \mathrm{M} \mathrm{NaOH}$. Therefore, the final concentration of $\mathrm{NaOH}$ was $1 \mathrm{M}$ in all samples. Excess of BSA was added to each sample to eliminate absorbance differences between nanoparticle samples and calibrators caused by the presence of hydrolyzed BSA in the former. After $72 \mathrm{~h}$ of incubation on the rotator $(10 \mathrm{rpm}, 360$ degrees) at $+37{ }^{\circ} \mathrm{C}$ absorbance at $382 \mathrm{~nm}$ was measured (Figure S1). The absorbance of the zero calibrator (1\% BSA in $1 \mathrm{M} \mathrm{NaOH})$ was subtracted from the absorbances of all other samples. The calibration curve was obtained by linear regression analysis.

Scanning electron microscopy (SEM). The nanoparticle solution in water (1-10 $\mu \mathrm{g} / \mathrm{ml}$ ) was drop-cast on a silicon substrate using a micropipette and dried at room temperature overnight. Samples were analyzed by field emission scanning electron microscope FEI Quanta 650FEG.

\section{Conjugation of BSA/hemin nanoparticles with protein $G$}

Glutaraldehyde was diluted to $2 \%$ with phosphate buffer $(\mathrm{pH} 7)$, then the $\mathrm{pH}$ of the mixture was adjusted to 7 with $1 \mathrm{M} \mathrm{NaOH}$. BSA/hemin nanoparticles were diluted to 2 $\mathrm{mg} / \mathrm{ml}$ with phosphate buffer $(\mathrm{pH} 7)$; then $4 \mathrm{ml}$ of BSA/hemin nanoparticles were slowly added with stirring into $4 \mathrm{ml}$ of $2 \%$ glutaraldehyde. The reaction was carried out for 60 min at $+37{ }^{\circ} \mathrm{C}$ on a rotator (10 rpm, 360 degrees). Nanoparticles were sonicated (18 W, $100 \%$ amplification, $3 \mathrm{~mm}$ probe, $10 \mathrm{~s}$ ). After that, absorbance at $700 \mathrm{~nm}$ was measured. Then, nanoparticles were washed three times with a phosphate buffer $(\mathrm{pH} 7)$ by centrifugation at $20000 \mathrm{~g}$ for $60 \mathrm{~min}$. Pellet was redispersed after each wash by sonication (10 W, 60\% amplification, $3 \mathrm{~mm}$ probe, $10 \mathrm{~s}$ ). The final volume of glutaraldehydeactivated nanoparticles was $4 \mathrm{ml}$. The concentration of nanoparticles was determined by measuring absorbance at $700 \mathrm{~nm}$. The suspension of glutaraldehyde-activated 
nanoparticles was divided into 4 portions, $1 \mathrm{ml}$ each. To three of the four portions protein $\mathrm{G}(10 \mathrm{mg} / \mathrm{ml})$ was added to reach protein $\mathrm{G}$ to nanoparticles ratios of 5,20 , and $80 \mu \mathrm{g} / \mathrm{mg}$. To the fourth portion, BSA $(192 \mathrm{mg} / \mathrm{ml})$ was added $(80 \mu \mathrm{g}$ of BSA per $1 \mathrm{mg}$ of nanoparticles). The resulting suspensions were briefly vortexed and incubated for $16 \mathrm{~h}$ at $+37^{\circ} \mathrm{C}$ on a rotator (10 rpm, 360 degrees). Blocking of remaining free aldehyde groups was performed by adding $1 \mathrm{ml}$ of BSA solution $(192 \mathrm{mg} / \mathrm{ml} \mathrm{mg} / \mathrm{ml}$ ) followed by $60 \mathrm{~min}$ incubation in the same conditions. BSA/hemin nanoparticles conjugated with protein $\mathrm{G}$ or BSA were washed from non-bound proteins as described above and redispersed in $1 \mathrm{ml}$ of deionized water. The concentration of nanoparticles was determined by measuring absorbance at $700 \mathrm{~nm}$. Depending on the initial amount of protein G or BSA, the resulting nanoparticles were designated as G5, G20, G80, or BSA, for example, NPC-G5 or NP20BSA.

Direct IgG detection by BSA/hemin nanoparticles conjugated with protein $G$

Human IgG was diluted to 10,1 , and $0.1 \mu \mathrm{g} / \mathrm{ml}$ in $0.2 \mathrm{M}$ carbonate buffer, pH 9.6. BSA was diluted to $10 \mu \mathrm{g} / \mathrm{ml}$ in the same buffer. One hundred microliters of these solutions were added into the wells of the 96 -well plate and incubated at $+37{ }^{\circ} \mathrm{C}$ for 2 hours. Further, all the assay steps were performed at $+37^{\circ} \mathrm{C}$ on an orbital shaker (400 rpm). The plate was washed three times with PBT (300 $\mu \mathrm{l}$ per well), then $200 \mu \mathrm{l}$ of the blocking solution (PBT+1\% casein+1\% BSA, pH 7) was added. In 60 min wells were washed, and $100 \mu \mathrm{l}$ of nanoparticles diluted to $200 \mu \mathrm{g} / \mathrm{ml}$ in the blocking solution were added. The plate was incubated for 60 min and washed. Wells were filled with $100 \mu l$ of substrate solution $(8.7 \mathrm{ml}$ of $0.1 \mathrm{M}$ acetate buffer, $\mathrm{pH} 5 ; 0.3 \mathrm{ml}$ of $0.1 \mathrm{M}$ phosphate-citrate buffer, $\mathrm{pH}$ 5; $1 \mathrm{ml}$ of $10 \mathrm{mg} / \mathrm{ml}$ TMB in DMSO; $10 \mu \mathrm{l}$ of 30\% H2O2) and incubated for 30 min. The reaction was stopped by the addition of $100 \mu \mathrm{l}$ of $2 \mathrm{M} \mathrm{H} 2 \mathrm{SO} 4$. Absorbance at $450 \mathrm{~nm}$ was measured by a microplate reader.

\section{Substrate buffers screening}

Human IgG was diluted to $1 \mathrm{\mu g} / \mathrm{ml}$ in $0.2 \mathrm{M}$ carbonate buffer, $\mathrm{pH}$ 9.6. One hundred microliters of these solutions were added into the wells of the 96-well plate. Control wells remained empty. Plates were incubated at $+37^{\circ} \mathrm{C}$ for 2 hours. Further, all the assay steps were performed at $+37^{\circ} \mathrm{C}$ on an orbital shaker (400 rpm). Wells (both coated and uncoated) were washed three times with PBT (300 $\mu$ l per well), then $200 \mu \mathrm{l}$ of the blocking solution (PBT+1\% casein+1\%BSA, pH 7) was added. In 60 min wells were washed, and $100 \mu \mathrm{l}$ of NP20-G80 or NP10-G20 diluted to $100 \mu \mathrm{g} / \mathrm{ml}$ in the blocking solution were added only to the IgG-coated wells. The plate was incubated for $60 \mathrm{~min}$ and washed. Wells were filled with $100 \mu$ l of substrate solution $(9 \mathrm{ml}$ of buffer; $1 \mathrm{ml}$ of $1 \mathrm{mg} / \mathrm{ml}$ TMB in DMSO; 10 $\mu \mathrm{l}$ of $30 \% \mathrm{H} 2 \mathrm{O} 2$ ) and incubated for $30 \mathrm{~min}$. The reaction was stopped by the addition of $100 \mu \mathrm{l}$ of $2 \mathrm{M} \mathrm{H} 2 \mathrm{SO} 4$. Absorbance at $450 \mathrm{~nm}$ was measured by a microplate reader.

\section{Labeling of IgG with fluorescein}

Fluorescein isothiocyanate (FITC) was diluted to $1 \mathrm{mg} / \mathrm{ml}$ in DMSO. $100 \mu \mathrm{l}$ of the resulting solution was added to $400 \mu \mathrm{l}$ of $1 \mathrm{mg} / \mathrm{ml} \mathrm{IgG}$ in $0.1 \mathrm{M}$ carbonate buffer, $\mathrm{pH}$ 9.5. The mixture was kept on a rotator (10 rpm, 360 degrees) for 2 hours at room temperature in the darkroom. Unbound FITC molecules were removed by dialysis versus PB using a Slide-A-Lyzer device (Figure S2). FITC labeling ratio (3.565) was estimated according to ref [The, 1970].

\section{protein $G$}

Quantitation of IgG binding by the BSA/Hemin nanoparticles conjugated with

Nanoparticles and IgG-FITC were diluted to $80 \mu \mathrm{g} / \mathrm{ml}$ and $5 \mu \mathrm{g} / \mathrm{ml}$ respectively with PBT supplemented with $1 \%$ casein and 1\% BSA. The resulting solutions were mixed 1:1 
in a total volume of $400 \mu \mathrm{l}$ and kept on a rotator for 1 hour at $+37^{\circ} \mathrm{C}$ in the darkroom. Calibrators were prepared by diluting IgG-FITC in the same buffer. Nanoparticles were removed by centrifugation (20000 g, $60 \mathrm{~min}) ; 100 \mu \mathrm{l}$ of supernatants and calibrators were added into the black 96-well plates, fluorescence $(480 / 512 \mathrm{~nm})$ was measured by a microplate reader.

\section{Polyacrylamide gel electrophoresis (SDS-PAGE)}

Gels were prepared using $0.1 \mathrm{M}$ TRIS-HCl buffer, $\mathrm{pH} 8.8$, which contained $0.1 \%$ SDS. TRIS-glycine buffer $\mathrm{pH} \sim 8.3$ was used as an electrode buffer. Electrophoresis was performed without using a concentrating gel. The gel thickness was $0.75 \mathrm{~mm}$. Samples were mixed with a sample buffer (10\% SDS, 0.1 M EDTA, 50\% glycerol, 0.5 M TRIS, $0.1 \%$ Bromphenol blue, with or without $5 \%$ beta-mercaptoethanol) $5: 1,10 \mu \mathrm{L}$ of the mixture was applied to the gel. In some experiments, samples were warmed up at +95 ${ }^{\circ} \mathrm{C}$ before applying to the gel. Electrophoresis was performed at a constant voltage of 200 $\mathrm{V}$. The gels were stained for 60 min with Coomassie G-250 and then destained with a fixing solution ( $20 \%$ methanol, $7.5 \%$ acetic acid). Destained gels were photographed using a smartphone. Photographs were cropped and presented without any color manipulations.

\section{Detection of $\operatorname{tg} G$}

Tetanus toxoid was diluted to $2 \mu \mathrm{g} / \mathrm{ml}$ in $0.2 \mathrm{M}$ carbonate buffer, $\mathrm{pH}$ 9.6. One hundred microliters of this solution were added into the wells of the 96-well plate. Plates were incubated at $+37^{\circ} \mathrm{C}$ for 2 hours. Further, all the assay steps were performed at +37 ${ }^{\circ} \mathrm{C}$ on an orbital shaker (400 rpm). Wells were washed three times with PBT (300 $\mu \mathrm{l} \mathrm{per}$ well), then $200 \mu \mathrm{l}$ of the blocking solution (PBT+1\% casein $+1 \% \mathrm{BSA}, \mathrm{pH} 7$ ) was added. In 60 min wells were washed, and $100 \mu$ of tlgG four-fold diluted in blocking buffer or in blocking buffer containing $5 \%$ rabbit serum $(100,25,6.25,1.56,0.39,0.097$, and 0 $\mathrm{mIU} / \mathrm{ml}$ ). Plates were incubated for $60 \mathrm{~min}$, washed, and filled with $100 \mu \mathrm{l}$ of nanoparticles diluted to $200 \mu \mathrm{g} / \mathrm{ml}$ in the blocking solution. The plate was incubated for $60 \mathrm{~min}$ and washed. Wells were filled with $100 \mu \mathrm{l}$ of substrate solution $(9 \mathrm{ml}$ of $0.1 \mathrm{M}$ citrate-imidazole buffer, $\mathrm{pH} 4$ or citrate-phosphate buffer, $\mathrm{pH} 4 ; 1 \mathrm{ml}$ of $1 \mathrm{mg} / \mathrm{ml}$ TMB in DMSO; $10 \mu \mathrm{l}$ of $30 \% \mathrm{H} 2 \mathrm{O} 2$ ) and incubated for $30 \mathrm{~min}$. The reaction was stopped by the addition of 100 $\mu \mathrm{l}$ of $2 \mathrm{M} \mathrm{H} 2 \mathrm{SO} 4$. Absorbance at $450 \mathrm{~nm}$ was measured by a microplate reader.

\section{Results}

Synthesis and characterization of BSA/Hemin nanoparticles

Synthesis and characterization of BSA/Hemin nanoparticles

BSA/hemin nanoparticles were synthesized by the desolvation method, which is based on the dropwise addition of ethanol to the solution containing BSA and hemin (Figure 1A). The key feature of the synthesis process is that the $\mathrm{pH}$ of the solution was adjusted to 11. It is known that the $\mathrm{pH}$ of the BSA solution should be away from an isoelectric point in the course of desolvation. An increase in the $\mathrm{pH}$ decreases both size and yield of nanoparticles. Typically, the pH of BSA solution is kept between 7 and 9 [Langer, 2003], however, in this work pH was as high as 11 to provide better hemin solubility. Formed nanoparticles were stabilized by heating at $+70{ }^{\circ} \mathrm{C}$ [Weber, 2000] because conventional glutaraldehyde cross-linking led to aggregation. 

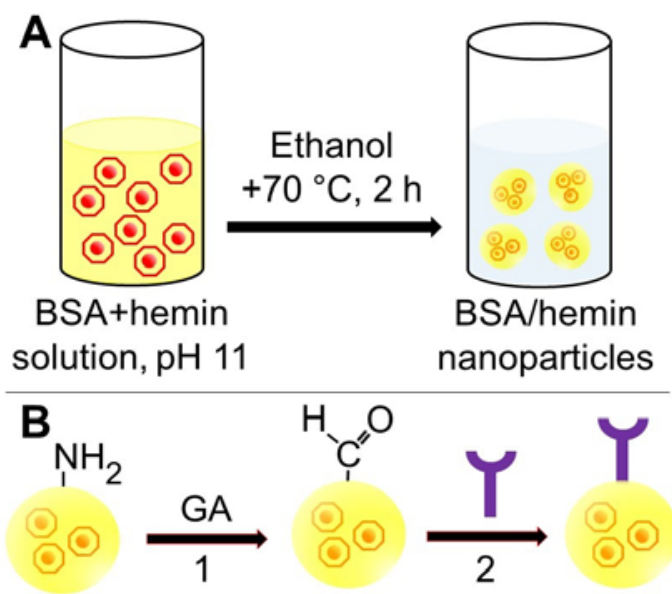

Figure 1. A - scheme of BSA/hemin nanoparticles preparation; B - scheme of conjugation of BSA/hemin nanoparticles with protein G. 1 - glutaraldehyde (GA) addition; 2 - addition of protein $\mathrm{G}$ (purple figure).

Usually, the volume of added ethanol varies from about 3 to $5 \mathrm{ml}$ per $1 \mathrm{ml}$ of BSA solution. The formation of nanoparticles can be monitored by visual assessment of suspension turbidity. However, in the presence of hemin, the color of the reaction mixture is dark brown, and visual assessment is hardly possible. Besides, the addition of the excess ethanol resulted in the formation of aggregates upon heat-driven stabilization. Therefore, the turbidity of the reaction mixture was monitored by measuring absorbance at $700 \mathrm{~nm}$ (hemin does not absorb at this wavelength Figure 2A). The addition of ethanol was stopped when the growth of absorbance was observed. This approach allowed the successful synthesis of BSA/hemin nanoparticles.

A
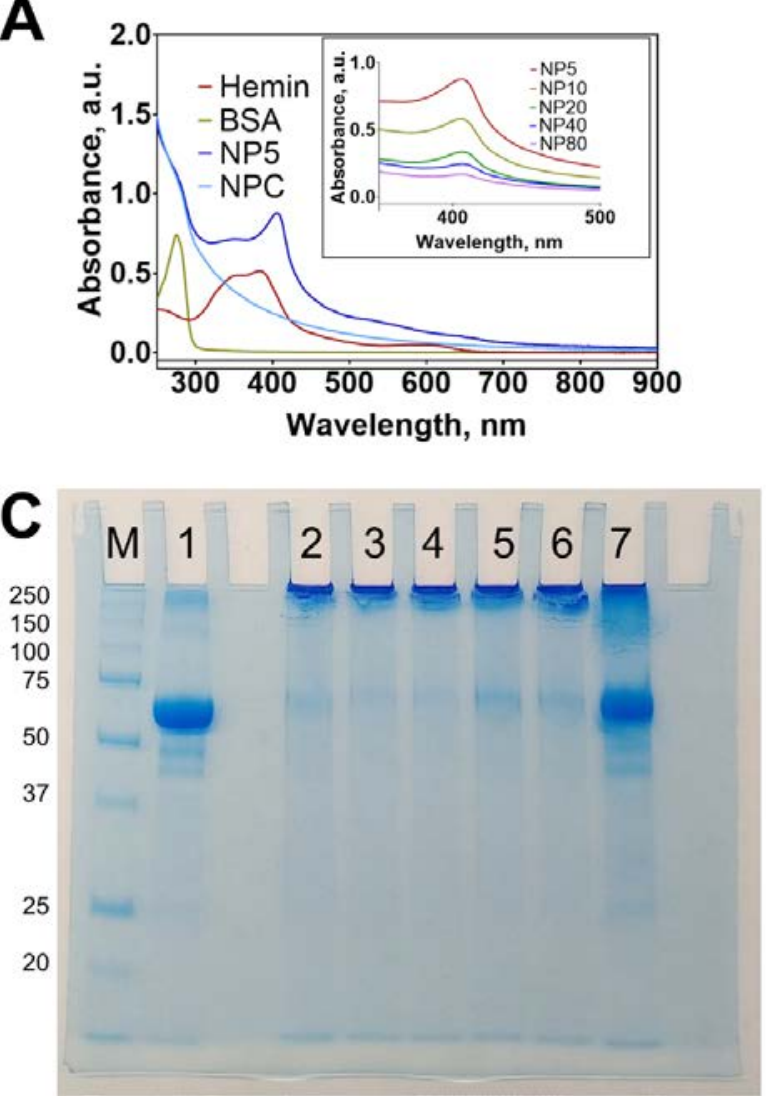

B NP5 NP10 NP20 NP40 NP80 NPC
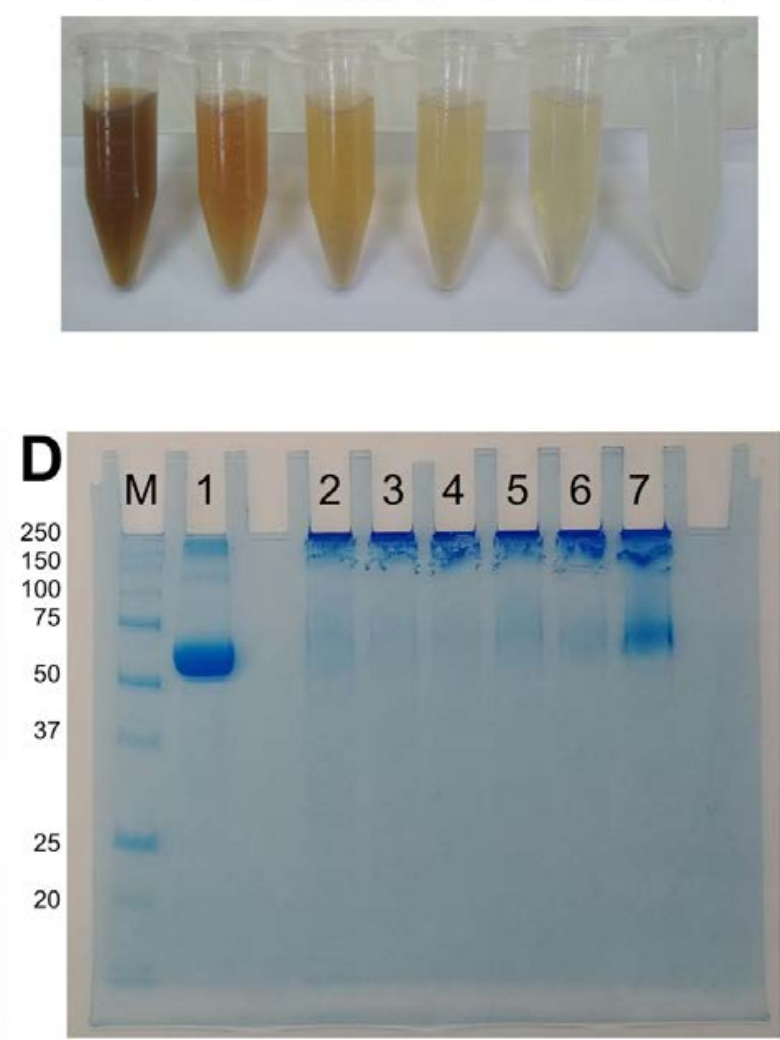

Figure 2. A - UV-vis absorbance spectra of BSA (1 mg/ml), hemin $(10 \mu \mathrm{g} / \mathrm{ml})$, and NPC and NP5 nanoparticles (both $250 \mu \mathrm{g} / \mathrm{ml}$ ). Inset - absorbance spectra of BSA/Hemin 
nanoparticles $(250 \mu \mathrm{g} / \mathrm{ml})$; B - suspensions of BSA/hemin nanoparticles; SDS-PAGE of BSA/hemin nanoparticles $(1 \mathrm{mg} / \mathrm{ml})$ with $(\mathrm{C})$ or without (D) heating at $+95^{\circ} \mathrm{C}$ : $\mathrm{M}$ - protein markers, 1 - BSA, 2 - NP5, 3 - NP10, 4 - NP20, 5 - NP40, 6 - NP80, 7 - NPC.

Dependence of hemin loading efficiency on initial BSA to hemin mass ratio was studied. The mass ratio varied from 5:1 to 80:1 (the resulting nanoparticles are designated accordingly as NP5, NP10, NP20, NP40, and NP80), besides control nanoparticles (designated as NPC) were prepared in the absence of hemin. Properties of BSA/hemin nanoparticles are summarized in Table 1 . The size of nanoparticles (hydrodynamic diameter, Dh) measured by DLS was in the range from 96 to $153 \mathrm{~nm}$. The polydispersity index of all nanoparticles was equal to or lower than 0.1 which means that they have a relatively narrow size distribution. Due to the high $\mathrm{pH}$ of the initial BSA solution and, hence, significant electrostatic repulsion of BSA molecules, the yield of nanoparticles was low (less than 40\%) as to conventional synthesis conditions [Langer, 2003]. Nanoparticles had a spherical shape (Figure 3) according to SEM.

Table 1. Properties of BSA/hemin nanoparticles

\begin{tabular}{|c|c|c|c|c|c|c|c|c|}
\hline Sample & $\begin{array}{c}\text { Volume, } \\
\mathrm{ml}\end{array}$ & $\begin{array}{c}\text { Concentration, } \\
\mathrm{mg} / \mathrm{ml}\end{array}$ & $\begin{array}{c}\mathrm{Dh}^{[\mathrm{ia]}} \\
\text { mean } \pm S \mathrm{~S}^{[\mathrm{b}]}\end{array}$ & $\begin{array}{c}\mathrm{PdI}[\mathrm{a}] \\
\text { mean } \pm \text { SD }\end{array}$ & $\begin{array}{c}\text { Zeta } \\
\text { potential, } \mathrm{mV}\end{array}$ & Yield, \%[c] & $A_{406}$ & $\begin{array}{l}\text { Hemin, } \\
\mu \mathrm{g} / \mathrm{mg}\end{array}$ \\
\hline NP5 & 4,5 & 5,1 & $137 \pm 2$ & $0,100 \pm 0,017$ & $-18,2$ & 14,3 & 0,879 & 34,7 \\
\hline NP10 & 8,4 & 11,7 & $155 \pm 3$ & $0,084 \pm 0,022$ & $-16,3$ & 61,4 & 0,582 & 16,8 \\
\hline NP20 & 8 & 7,5 & $119 \pm 4$ & $0,080 \pm 0,005$ & $-17,1$ & 37,5 & 0,337 & 9,9 \\
\hline NP40 & 7,8 & 8,1 & $111 \pm 0$ & $0,078 \pm 0,004$ & $-16,7$ & 39,5 & 0,247 & 6,1 \\
\hline NP80 & 7,6 & 2,5 & $96 \pm 11$ & $0,073 \pm 0,010$ & $-15,3$ & 11,9 & 0,169 & 6,8 \\
\hline NPC & 7,6 & 5,4 & $124 \pm 1$ & $0,061 \pm 0,010$ & $-17,3$ & 25,7 & 0,237 & 2,0 \\
\hline
\end{tabular}

There was no clear relationship between the mass of added hemin and the resulting particle diameter. This is not surprising because the size of desolvated protein nanoparticles depends on multiple factors including the quantity of loaded compound, the volume of non-solvent, as well as non-solvent addition regime [Storp, 2012, Paik, 2013]. In our experiments larger ethanol volume is required to induce albumin desolvation at lower hemin concentrations, indicating that hemin itself promotes aggregation of protein molecules. Moreover, the addition of ethanol was performed portion-by-portion with intervals, and the number of intervals depended on ethanol volume being various for each type of nanoparticle. Therefore, it should be concluded that the between-batch differences of the synthesis procedure were too large to unveil distinct patterns.

Synthesized nanoparticles were stored in deionized water at $+4{ }^{\circ} \mathrm{C}$ for 1 month. The hydrodynamic diameter of nanoparticles remained unchanged throughout this period. 

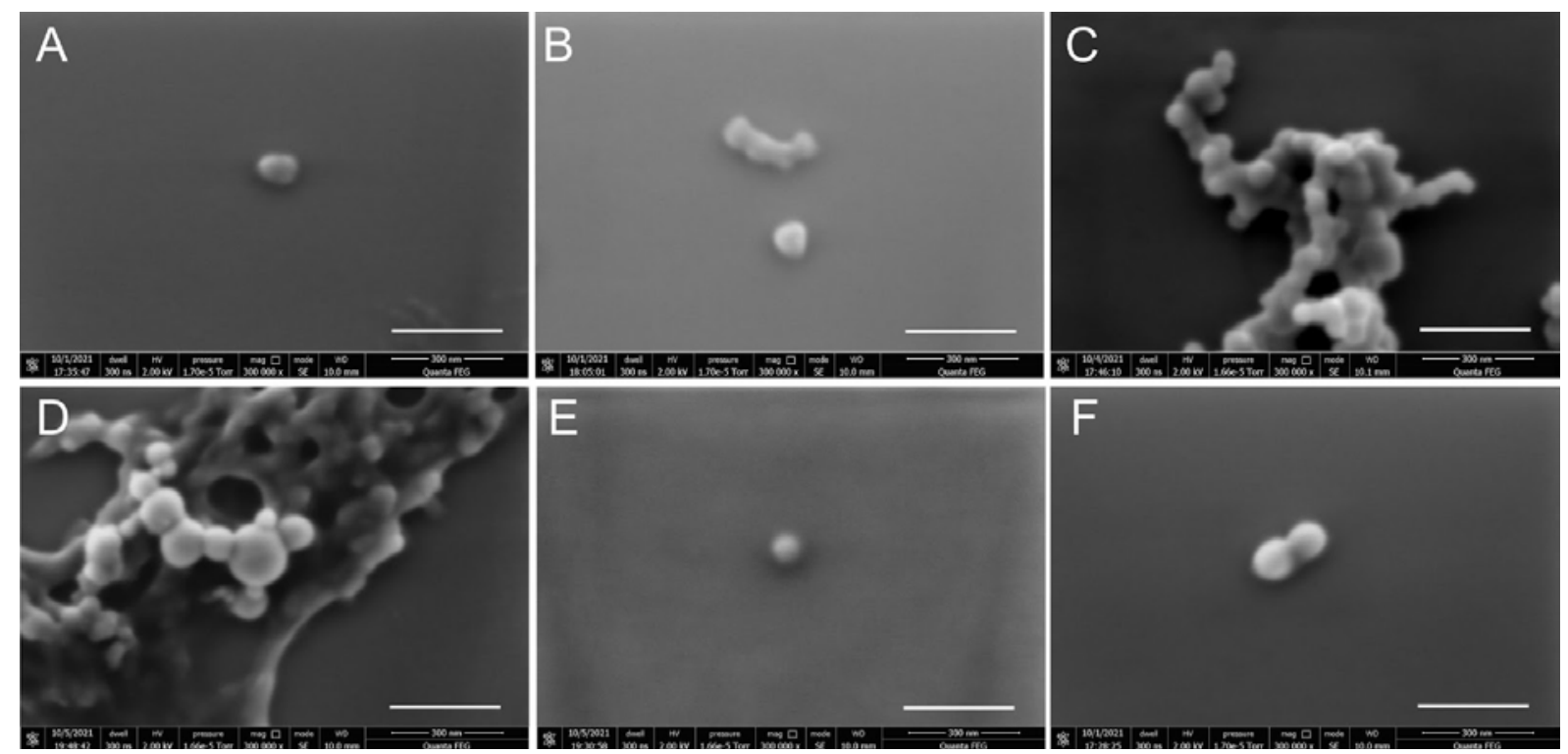

Figure 3. SEM images of BSA/hemin nanoparticles: NP5 (A), NP10 (B), NP20 (C), NP40 (D), NP80 (E), NPC (F). Scale bar is $300 \mathrm{~nm}$.

Loading of hemin was assessed by measuring the absorbance of hydrolyzed nanoparticles at $382 \mathrm{~nm}$. Results demonstrate that hemin loading reached $34.7 \mu \mathrm{g} / \mathrm{mg}$ at the lowest BSA to hemin ratio and gradually decreased at higher ratio values. Successful loading was easily detected even by visual inspection of nanoparticle solutions: the more hemin was added the darker was their color was (Figure 2B). A distinct peak with the maximum at $406 \mathrm{~nm}$ was observed for all hemin-loaded particles (NP5-NP80) but not for NPC (Figure 2A). Notably, this absorbance peak was red-shifted in relation to the absorbance maximum of pure hemin (382 nm). According to ref. [Makarska-Bialokoz, 2018] such a shift implies both formation of the BSA-Hemin complex and the change of iron oxidation state. The absorbance of BSA/Hemin nanoparticles at $406 \mathrm{~nm}$ was proportional to the initial hemin concentration, however, A406 is affected not only by the hemin but also particle light scattering which is higher for large nanoparticles.

SDS-PAGE was used to additionally characterize the structure of BSA/Hemin nanoparticles. Recently, we demonstrated that disulfide bonds maintain heat-stabilized BSA nanoparticle integrity [Khramtsov, 2021]. Nanoparticles were treated with betamercaptoethanol which is able to reduce protein disulfide bonds and applied to the gel. As expected, a distinct BSA band appeared in the NPC sample (Figure 2C,D), however, almost no BSA monomers were observed for hemin-containing nanoparticles. This effect was reproduced even under conditions of gel overload. (Figure S3). In the absence of beta-mercaptoethanol, no protein bands were observed in nanoparticle samples (data not shown). These results demonstrate that hemin itself can stabilize BSA nanoparticles. Despite the ability of BSA to non-covalently bind hemin is well known [De Simone, 2021], direct mixing of BSA with protoporphyrin-IX does not cause protein aggregation [Maitra, 2021]. Therefore, the mechanism of stabilization remains unclear.

\section{Conjugation of BSA/Hemin nanoparticles with Streptococcal protein $G$}

Nanoparticles were harnessed for IgG binding by conjugation with Streptococcal protein $\mathrm{G}$. This protein is able to recognize $\mathrm{Fc}$ and to a lesser extent Fab fragments of mammalian IgGs including human ones. The utilization of protein $G$ enables the preparation of universal diagnostic reagents for serological assays which can be used for the assessment of humoral immune response in vaccinated or infected individuals as well as in immunized laboratory animals. Herein we used a recombinant variant (G4223) of protein $\mathrm{G}$ expressed in E. coli having a molecular weight of $30 \mathrm{kDa}$ (Figure S3). G4223 has three IgG binding sites but lacks albumin binding sites. Properties of this recombinant 
protein have been recently studied [Bormotova, 2018]. Conjugation strategy included treatment of BSA/Hemin nanoparticles with 10-fold excess (ten carbonyl groups per one lysine) of glutaraldehyde which forms Schiff bases by reacting with primary amines located on the surface of nanoparticles. Being dialdehyde glutaric aldehyde provides multiple free carbonyl groups to which protein $\mathrm{G}$ molecules can be anchored. The initial ratio of protein $G$ to nanoparticles ratio was 5,20 , and $80 \mu \mathrm{g} / \mathrm{mg}$, besides control nanoparticles conjugated with BSA were prepared. The conjugation process is accompanied by a slight increase of nanoparticles' size (by 20-30 nm) and a change of zeta potential. Glutaraldehyde treatment made zeta potential more negative due to a decrease of primary amines number. Conjugation of nanoparticles with protein G/BSA shifted zeta potential to more positive values (Figure 4).

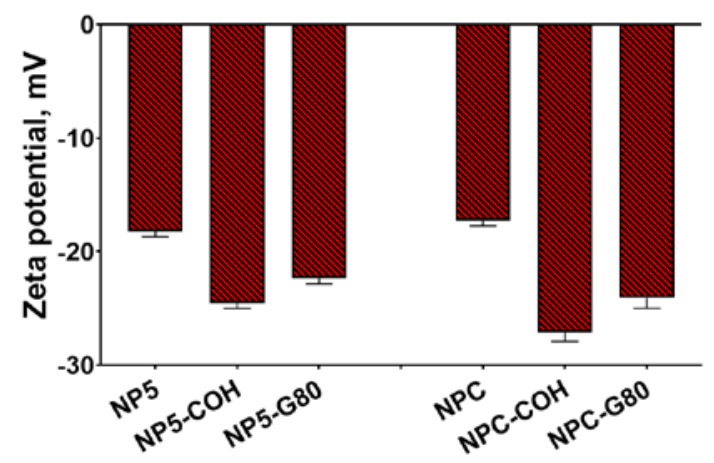

Figure 4. Change of nanoparticle zeta potential in the course of functionalization. "COH" index denotes glutaraldehyde-treated nanoparticles. $\mathrm{n}=3$, mean+SD.

The ability of BSA/Hemin nanoparticles conjugated with protein $\mathrm{G}$ to bind IgG was tested by ELISA-like assay. Human IgGs or BSA was adsorbed on the ELISA plates, then conjugates and TMB substrate solution were consequently added. Color development was observed for all hemin-containing nanoparticles carrying protein $\mathrm{G}$, but not for NPC or nanoparticles conjugated with BSA (Figure 5). In general, color intensity was proportional to hemin loading degree and protein $\mathrm{G}$ to nanoparticles ratio. Moreover, color development in positive samples confirms the peroxidatic activity of nanozymes. These results were reinforced by measuring the IgG binding capacity of nanoparticles conjugated with protein G of BSA. Human IgGs were labeled with FITC and incubated with nanoparticles. Removal of nanoparticles by centrifugation allowed for quantification of bound IgG-FITC by measuring fluorescence decrease. We tested nanoparticles loaded (NP5) and non-loaded (NPC) with hemin. The binding capacity of nanoparticles positively correlated with the initial protein $G$ to nanoparticle ratio (Figure 6). Notably, nanoparticles carrying BSA instead of protein $\mathrm{G}$ on their surface possessed markedly lower IgG-binding activity, indicating negligible non-specific interactions which is beneficial for immunoassay development. Almost two-fold difference of binding capacity between NP5-G20/G80 and NPC-G20/G80 can be explained by the lower number of protein $\mathrm{G}$ molecules attached to the latter because of the size (and, hence, specific area) of these nanoparticles are comparable. The reason for this difference is unclear and might be related to the mentioned structural peculiarities (see the last paragraph of the Section "Synthesis and characterization of BSA/Hemin nanoparticles") of hemin-loaded nanoparticles. Taken together the above results demonstrate that the interaction of BSA/Hemin nanoparticles with IgG is mediated precisely by protein $\mathrm{G}$ molecules. 

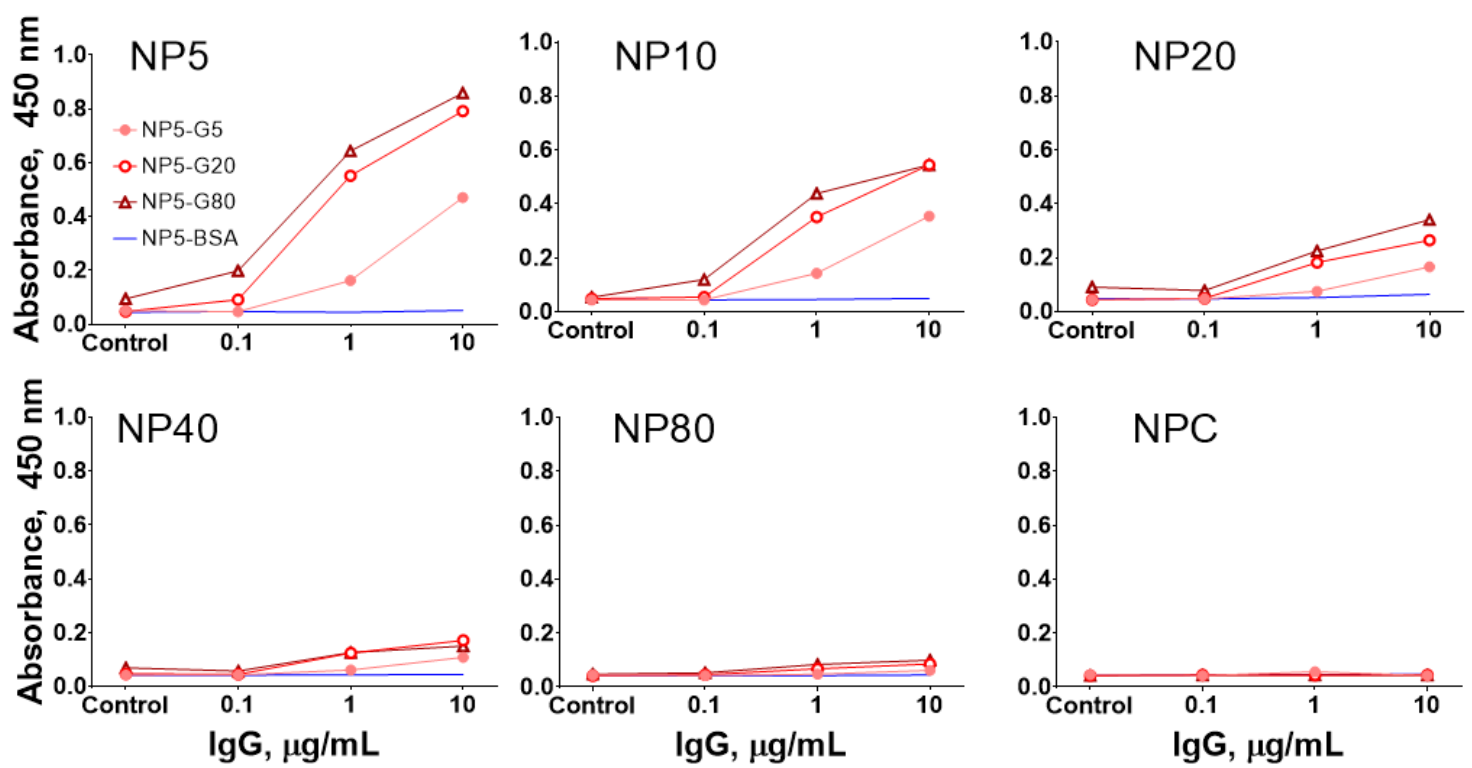

Figure 5. Direct detection of human IgG by various conjugates of BSA/Hemin nanoparticles conjugated with protein $\mathrm{G}$. Substrate buffer: 29 parts of $0.1 \mathrm{M}$ acetate buffer, pH 5; 1 part of $0.1 \mathrm{M}$ phosphate-citrate buffer, pH 5. n=1.

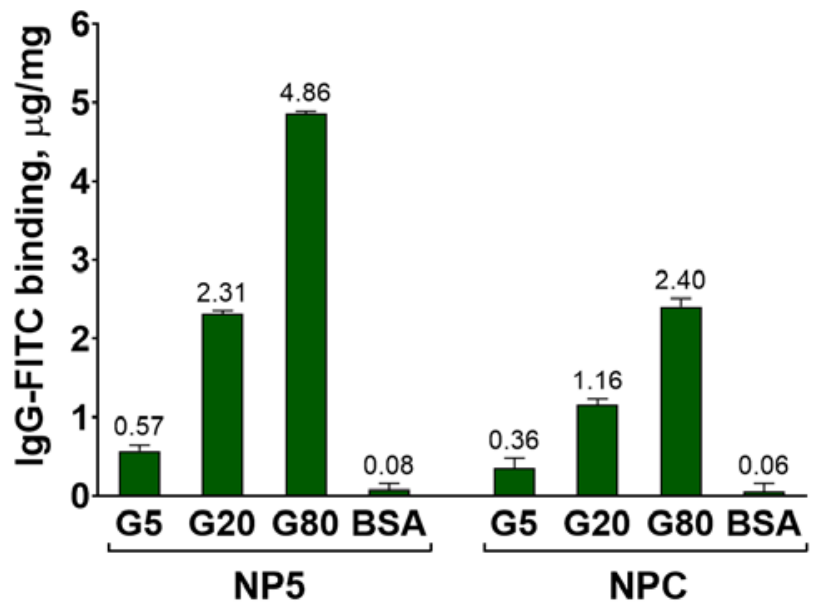

Figure 6. IgG binding capacity of NP5 and NPC conjugated with protein $\mathrm{G}$. $n=3$, mean+SD.

Development of an immunoassay for detection of antibodies against tetanus toxoid

The practical applicability of synthesized conjugates was demonstrated by the development of immunoassay detecting of anti-tetanus antibodies (tlgG). The development process consisted of several stages. First, the composition of substrate solution was chosen, then antigen concentration, conjugate type, and concentration were optimized.

For substrate optimization, a direct assay of IgG adsorbed on 96-well polystyrene plates was used. Various buffers with $\mathrm{pH}$ in the range of 2-10 were tested. Notably, the concentration of $\mathrm{H} 2 \mathrm{O} 2$ was $0.03 \%$ which is substantially higher than in ELISA. Since some buffers are capable of spontaneous H2O2 decomposition [Drozd, 2016; Luo, 2019], the color intensity of substrate alone ( 4450 control) was measured and compared with the absorbance of IgG-positive samples (A450 IgG). As expected, the catalytic activity of BSA/Hemin nanoparticles strongly depended on both substrate buffer $\mathrm{pH}$ and composition (Figures S4 and S5). The highest A450 IgG/A450 control values were observed in citrate-based buffers at $\mathrm{pH} 4$ and 5 whereas oxalate buffers provided a much 
lower response. More specifically, a citrate-ammonium buffer with $\mathrm{pH} 4$ produced the largest A450 lgG/A450 control value, however, a large difference of absorbance between duplicates was detected. Acetate, glycine, and HEPES buffers induced TMB oxidation in the absence of nanoparticles, being therefore inappropriate for application in the assay. At $\mathrm{pH} 6$ and higher almost no activity was detected.

In the following experiment, we tested 10 citrate-based buffers with $\mathrm{pH} 4$ and 5 . In total, higher absorbance values were obtained at pH 4 (Figure 7). Of interest, a citrateimidazole buffer was equally efficient at both $\mathrm{pH} 4$ and 5 and generated the highest absorbance in IgG-positive samples, however, the citrate-HEPES buffer produced the highest A450 IgG/A450 ratio (Figure S6). The imidazole group of proximal histidine plays an essential role in HRP catalytic activity by taking part in the formation of compound I. Moreover, free imidazole dramatically increases the catalytic activity of HRP mutants lacking proximal histidine [Newmyer, 1996].

We suggested that the influence of non-specific interaction between conjugate and immunosorbent on background signal of immunoassay is much higher in comparison with the absorption of pure substrate, therefore imidazole buffer with $\mathrm{pH} 4$ was chosen for further experiments.
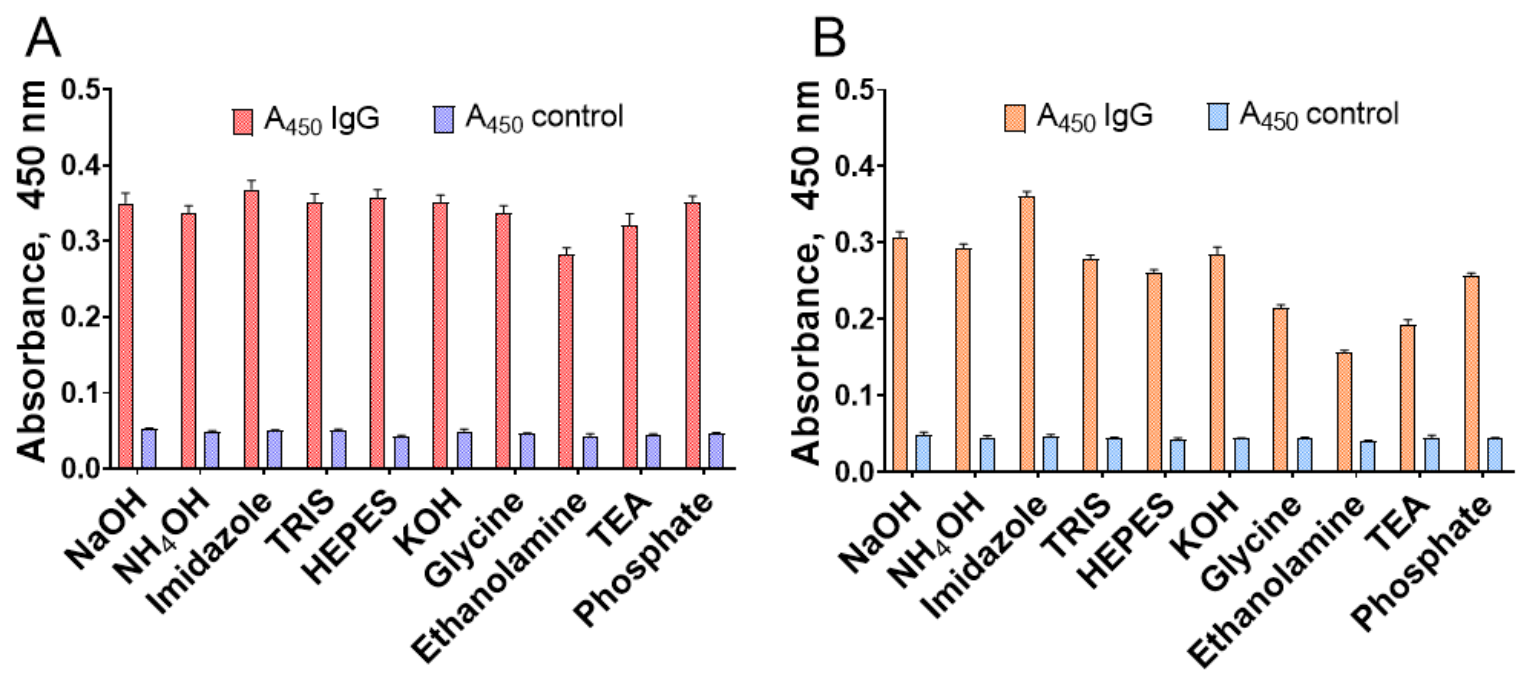

Figure 7. Absorbances of positive (10 $\mu \mathrm{g} / \mathrm{ml}$ of $\mathrm{IgG})$ and blank samples obtained with different citrate-based buffers: $\mathrm{pH} 4$ (A) and pH 5 (B). TEA - triethylamine.

Nanozymes usually have a relatively low affinity towards $\mathrm{H}_{2} \mathrm{O}_{2}$ therefore high concentrations of $\mathrm{H}_{2} \mathrm{O}_{2}$ are necessary to achieve adequate signal [Drozd, 2016]. We tested various amounts of hydrogen peroxide in substrate solution and revealed that $0.03-$ $0.12 \%$ is an optimal concentration (Figure 9A). Further increase of $\mathrm{H}_{2} \mathrm{O}_{2}$ concentration led to signal reduction, probably due to the oxidative destruction of hemin. 


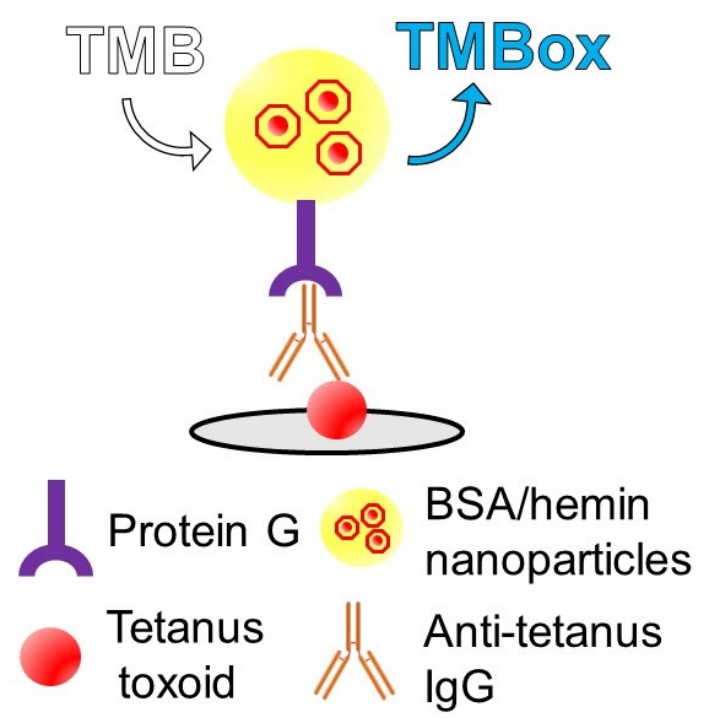

Figure 8. Principle of indirect immunoassay of antibodies against tetanus toxoid. TMBox is a blue-colored oxidized form of TMB.

Once the optimal substrate solution was chosen, an indirect immunoassay of IgGs against tetanus toxoid has been developed. Indirect immunoassay comprised the following steps: adsorption of tetanus toxoid on the polystyrene plates, blocking the nonoccupied sites of the well surface, the addition of tlgG, the addition of BSA/hemin nanoparticles conjugated with protein $G$, and signal generation with substrate solution (Figure 8). First of all, we optimized the concentration of tetanus toxoid. Typically, coating solution contains 1-10 $\mu \mathrm{g} / \mathrm{ml}$ of antigen [Crowther, 2009]. Wells were coated with 2, 10, and $50 \mu \mathrm{g} / \mathrm{ml}$ tetanus toxoid, and almost identical dose-response curves were obtained (Figure 9B). Therefore, $2 \mu \mathrm{g} / \mathrm{ml}$ solution of tetanus toxoid was used in further experiments. Next, the optimal type of BSA/hemin conjugate and its concentration were chosen. A larger concentration of nanoparticles provides a higher chance of interaction between nanoparticles and captured analyte (in this case tlgG), thus increasing generated signal per one analyte molecule. A possible undesirable consequence of high conjugate concentration is increased background signal caused by non-specific interaction between nanoparticles and immunosorbent. The same trade-off is true for the number of recognition molecules per nanoparticle. The more molecules are attached to a single nanoparticle, the higher the probability of both specific and nonspecific interactions. Four conjugates that provided the largest absorbance values in experiments with direct IgG detection were tested: NP5-G20, NP5-G80, NP10-G20, and NP10-G80. Concentrations of nanoparticles were 0.1 and $0.2 \mathrm{mg} / \mathrm{ml}$. Conjugates NP5-G80 and NP5G20 at $0.2 \mathrm{mg} / \mathrm{ml}$ provided better absorbance values (Figure 9C,D). However, poor between-replicates reproducibility was observed for NP5-G80 (and some other conjugates) even in zero calibrators. An increase in casein concentration did not resolve this issue. In additional experiments, we observed color development in substrate controls, which indicated that the instability of citrate-imidazole buffer was a source of errors. For this reason, thereafter we used a more traditional phosphate-citrate buffer, $\mathrm{pH}$ 4. 

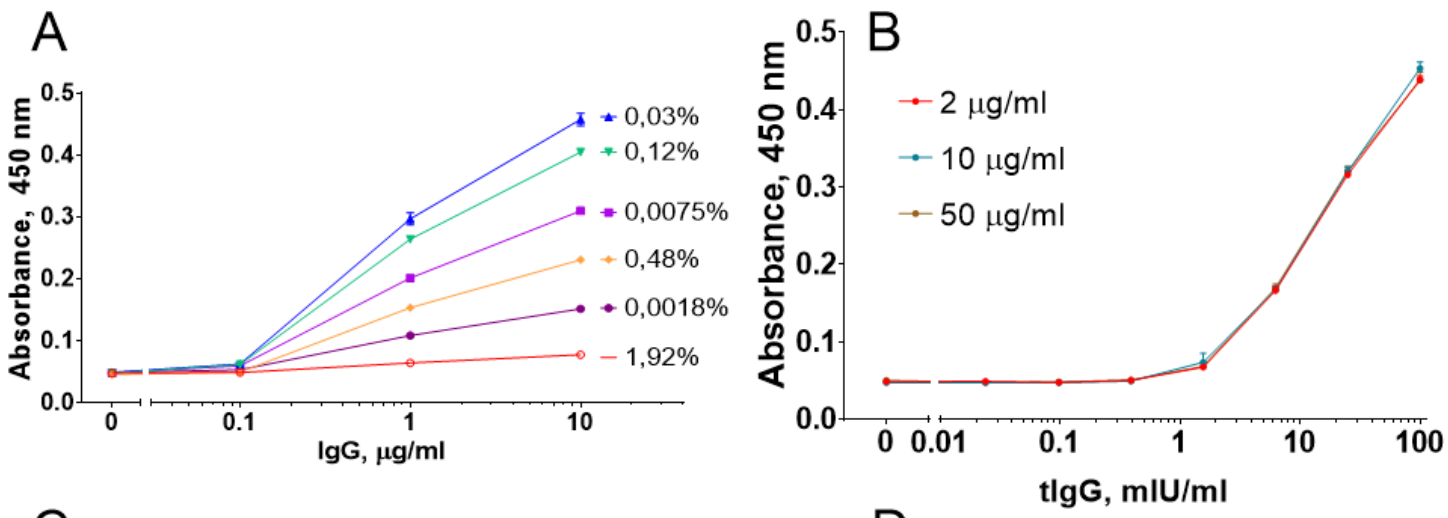

C
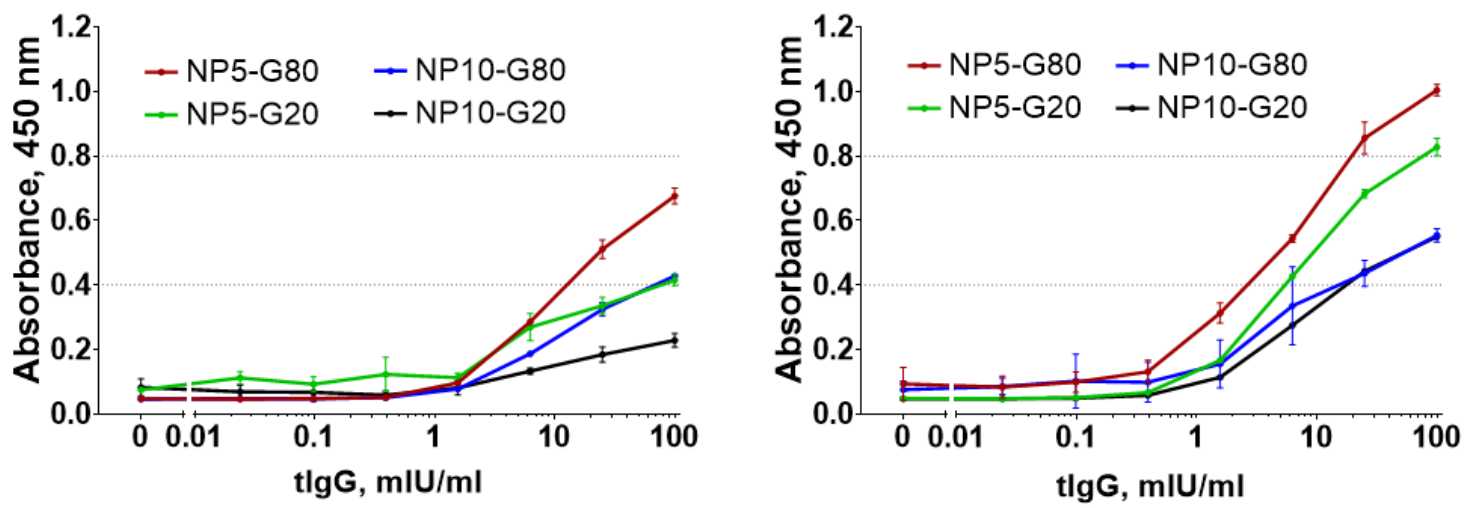

Figure 9. Optimization of immunoassay parameters: hydrogen peroxide concentration $(A)$; tetanus toxoid concentration $(B)$; concentration of nanozymes - 0.1 $\mathrm{mg} / \mathrm{ml}(\mathrm{C})$ and $0.2 \mathrm{mg} / \mathrm{ml}(\mathrm{D})$. Substrate buffer: $0.1 \mathrm{M}$ citrate-imidazole buffer, $\mathrm{pH}$ 4. $\mathrm{n}=3$, mean \pm SD.

The practical applicability of BSA/hemin nanoconjugates for analyte measurement in real samples was confirmed by detecting tlgGs in blood serum. Due to the high seroprevalence of antibodies against tetanus, it is quite a challenging task to obtain human serum that does not contain antibodies against tetanus toxoid, therefore pooled rabbit serum spiked with tlgG was used. The absence of tlgG in rabbit serum was confirmed by ELISA. One of the main purposes of antibody assays is discrimination between protected and non-protected individuals. For tlgG, a concentration of $100 \mathrm{mlU} / \mathrm{ml}$ is the threshold of protection. To ensure better assay resolution, serum dilution (1/20) was adjusted so that the protective concentration is in the steep region of the dose-response curve (Figure 10). Reproducibility was significantly improved in comparison with optimization experiments, however, absorbance values became lower as a result of both suboptimal conjugate (NP5-G20) and substrate usage. The limit of tlgG detection was $0.57 \mathrm{mlU} / \mathrm{ml}$ (mean+3xSD of control) despite being substantially higher than that of ELISA, whose analytical sensitivity reaches $0.02 \mathrm{mlU} / \mathrm{ml}$ [Kristiansen, 1997], but still enough to perform antibody quantification in vaccinated persons. The important result of the present study is that the desolvation method provides opportunities for the preparation of diagnostic reagents based on the application of enzyme mimics. Entrapment of enzyme mimics into albumin nanoparticles endows them with colloidal stability and provides multiple groups for functionalization. 


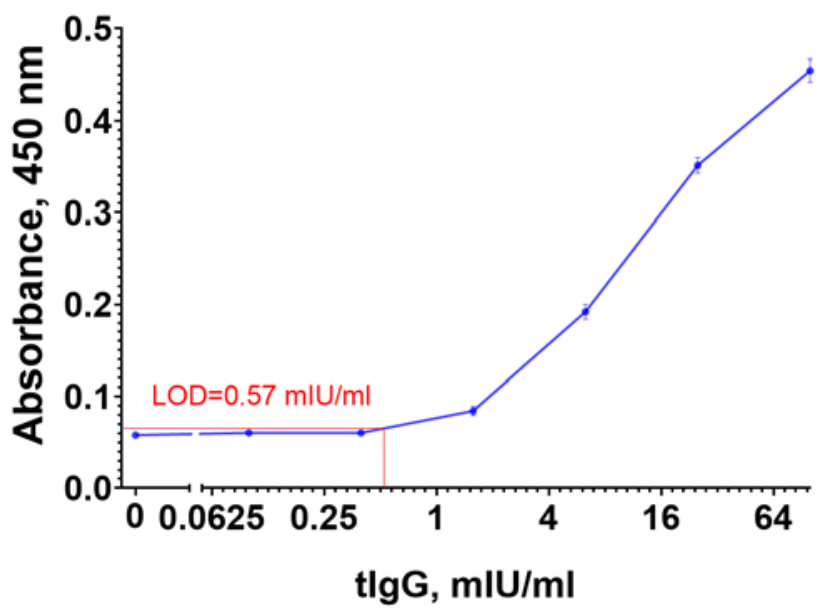

Figure 10. Dose-response curve of tlgG assay in $5 \%$ rabbit serum. Conjugate: NP5-G20; substrate buffer: $0.1 \mathrm{M}$ phosphate-citrate buffer, $\mathrm{pH}$ 4. $\mathrm{n}=3$, mean $\pm \mathrm{SD}$. LOD - limit of detection.

\section{Conclusion}

Hemin-loaded albumin nanoparticles were synthesized and applied for colorimetric detection of anti-tetanus IgG. Nanoparticles had homogeneous size distribution and good colloidal stability upon storage, however, the efficiency of the nanozymes-based diagnostic reagents was lower in comparison with peroxidase conjugates. We suggest that the desolvation method could be used for simultaneous stabilization and functionalization of enzyme mimics with higher catalytic activity.

\section{Supporting Information summary paragraph}

Additional figures were placed in supporting information

\section{Acknowledgments}

The reported study was funded by RFBR research project 19-015-00408 and by the Ministry of Science and Higher Education of the Russian Federation within the framework of the Russian State Assignment under contract No. AAAA-A19119112290010-7

\section{Conflict of Interest}

The authors declare no conflict of interest.

\section{References}

Y. Huang, J. Ren, X. Qu, Chem. Rev. 2019, 119, 4357. DOI:10.1021/acs.chemrev.8b00672

B. Das, J. L. Franco, N. Logan, P. Balasubramanian, M. I. Kim, C. Cao, NanoMicro Lett. 2021, 13, 193. DOI:10.1007/s40820-021-00717-0

S. Aydin, Peptides 2015, 72, 4. DOI:10.1016/j.peptides.2015.04.0

L. Gao, J. Zhuang, L. Nie, J. Zhang, Y. Zhang, N. Gu, T. Wang, J. Feng, D. Yang, S. Perrett, X. Yan, Nat. Nanotechnol. 2007, 2, 577-583. DOI: 10.1038/nnano.2007.260

L. Shen, D. Ye, H. Zhao, J. Zhang, Anal. Chem, 2020, 93, 1221. DOI:10.1021/acs.analchem.0c04084

G. Zhang, P. K. Dasgupta, Anal. Chem. 1992, 64, 517-522. DOI:10.1021/ac00029a013

Y. Ikariyama, S. Suzuki, M. Aizawa, Anal. Chem. 1982, 54, 1126-1129. DOI:10.1021/ac00244a026 
Y. Ikariyama, S. Suzuki, M. Aizawa, Anal. Chim. Acta 1984, 156, 245-252. DOI:10.1016/s0003-2670(00)85555-5

G. De Simone, A. di Masi, P. Ascenzi, Int. J. Mol. Sci. 2021, 22, 10086. DOI:10.3390/ijms221810086

M. Dong, L. Zhang, R. Li, R. Li, S. Li, Y. Jiang, Y. Qiao, Z. Duan, Q. Wang, H. Wang, RSC Adv. 2016, 6, 47595-47599. DOI: 10.1039/c6ra07139b

L. N. Grinberg, P. J. O'Brien, Z. Hrkal, Free Radical Biol. Med. 1999, 27, 214-219. DOI:10.1016/s0891-5849(99)00082-9

C. Weber, C. Coester, J. Kreuter, K. Langer, Int. J. Pharm. 2000, 194, 91-102. DOI: 10.1016/S0378-5173(99)00370-1

Y. Zhang, X.Yue, B. Kim, S. Yao, M. V. Bondar, K. D. Belfield, ACS Appl. Mater. Interfaces, 2013, 5, 8710. DOl:10.1021/am402361w

I. Zare, D.M. Chevrier, A. Cifuentes-Rius, N. Moradi, Y. Xianyu, S. Ghosh, L. Trapiella-Alfonso, Y. Tian, A. Shourangiz-Haghighi, S. Mukherjee, K. Fan, M.R. Hamblin, Mater. Today 2021, DOI: 10.1016/j.mattod.2020.10.027

M.-J. Lee, E.-S. Lee, T.-H. Kim, J.-W. Jeon, Y.T. Kim, B.-K. Oh, Nano Convergence, 2019, 6, 37. DOI: 10.1186/s40580-019-0210-5

G. H. Beaven, S.-H. Chen, A. D'albis, W. B. Gratzer, Eur. J. Biochem. 1974, 41, 539-546. DOI:10.1111/j.1432-1033.1974.tb03295.x

X. Yu, Z. Xu, X. Wang, Q. Xu, J. Chen, Mater. Sci. Eng., C. 2020, 109, 110627. DOI:10.1016/j.msec.2020.110627

K. H. Winterhalter, E. R. Huehns, J. Biol. Chem. 1964, 239, 3699.

J. Zhu, Y. Li, L. Li, J. Wang, H. Wang, W. Hong, K. Hao, Y. Xue, B. Chen, Z. Wang, Int. J. Nanomed. 2018, 13, 5523-5536. DOI:10.2147/IJN.S168574

M. Francisca Gómez-Rico, R. Font, A. Fullana, I. Martín-Gullón, J. Anal. Appl. Pyrolysis 2005, 74, 421. DOI:10.1016/j.jaap.2004.11.029

T. H. The, T. E. Feltkamp, Immunology 1970, 18, 865-873.

K. Langer, S. Balthasar, V. Vogel, N. Dinauer, H. Von Briesen, D. Schubert, Int. J. Pharm. 2003, 257, 169-180. DOI: 10.1016/S0378-5173(03)00134-0

B. v. Storp, A. Engel, A. Boeker, M. Ploeger, K. Langer, J. Microencapsulation, 2012, 29, 138. DOI: 10.3109/02652048.2011.635218

S. Y. Paik, H. H. Nguyen, J. Ryu, J. H. Che, T. S. Kang, J. K. Lee, C.W. Song, S. Ko, Food Chem. 2013, 141, 695-701. DOI:10.1016/j.foodchem.2013.04.059

M. Makarska-Bialokoz, Spectrochim. Acta, Part A 2018, 193, 23-32. DOI:10.1016/j.saa.2017.11.063

P. Khramtsov, T. Kalashnikova, M. Bochkova, M. Kropaneva, V. Timganova, S. Zamorina, M. Rayev, Int J Pharm. 2021, 599, 120422. DOI: 10.1016/j.ijpharm.2021.120422.

D. Maitra, B. M. Pinsky, A. Soherawardy, H. Zheng, R. Banerjee, M. B. Omary, J. Biol. Chem. 2021, 297, 100778. DOl:10.1016/j.jbc.2021.100778

E.A. Bormotova, T.V. Gupalova, Bull. Exp. Biol. Med. 2018, 165, 373-377 DOI:10.1007/s10517-018-4173-z

M. Drozd, M. Pietrzak, P. G. Parzuchowski, E. Malinowska, Anal. Bioanal. Chem. 2016, 408, 8505-8513. DOI:10.1007/s00216-016-9976-Z

Y. Luo, R. Shen, T. Li, C. Xiong, G. Li, L. Ling, Talanta 2019, 196, 493-497. DOI: 10.1016/j.talanta.2018.12.064

S. L. Newmyer, J. Sun, T. M. Loehr, P. R. Ortiz de Montellano, Biochemistry 1996, 35, 12788-12795. DOI:10.1021/bi9609331

J. Crowther, The ELISA guidebook. 2nd ed., Humana, New York, 2009, p. 44.

M. Kristiansen, H. Aggerbeck, I. Heron, APMIS 1997, 105, 843. DOI:10.1111/j.1699-0463.1997.tb05093.x 
Supporting information

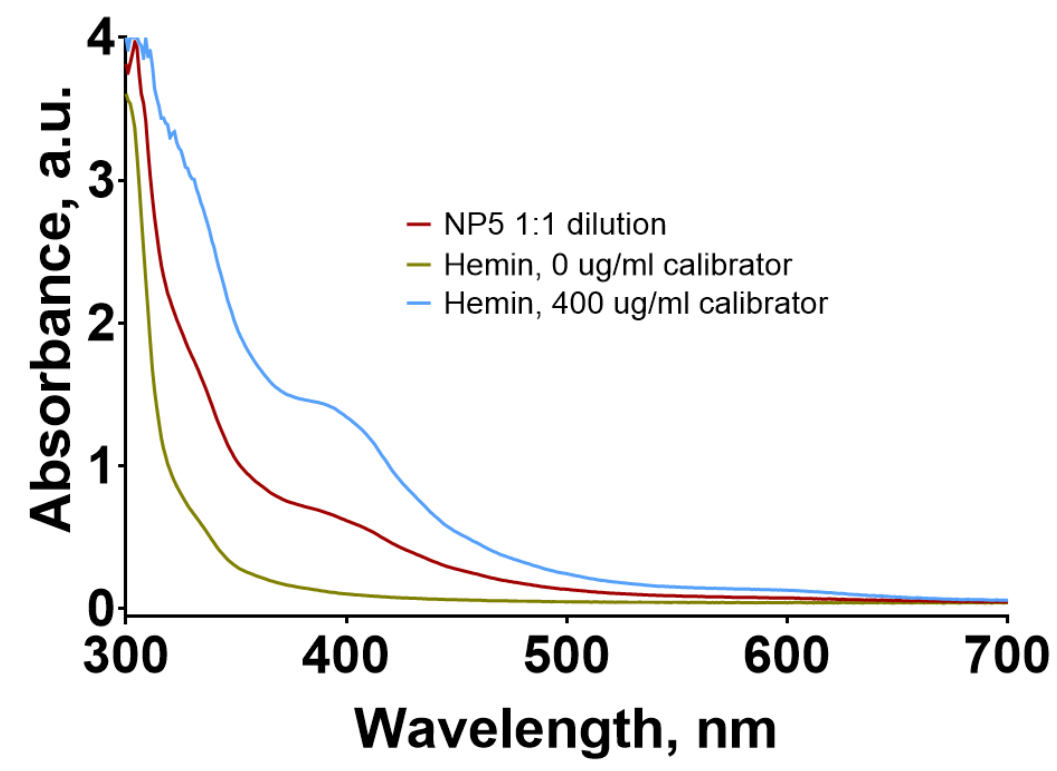

Figure S1. Quantification of hemin loading. Absorption spectra of hemin calibrators and NP5 nanoparticles.

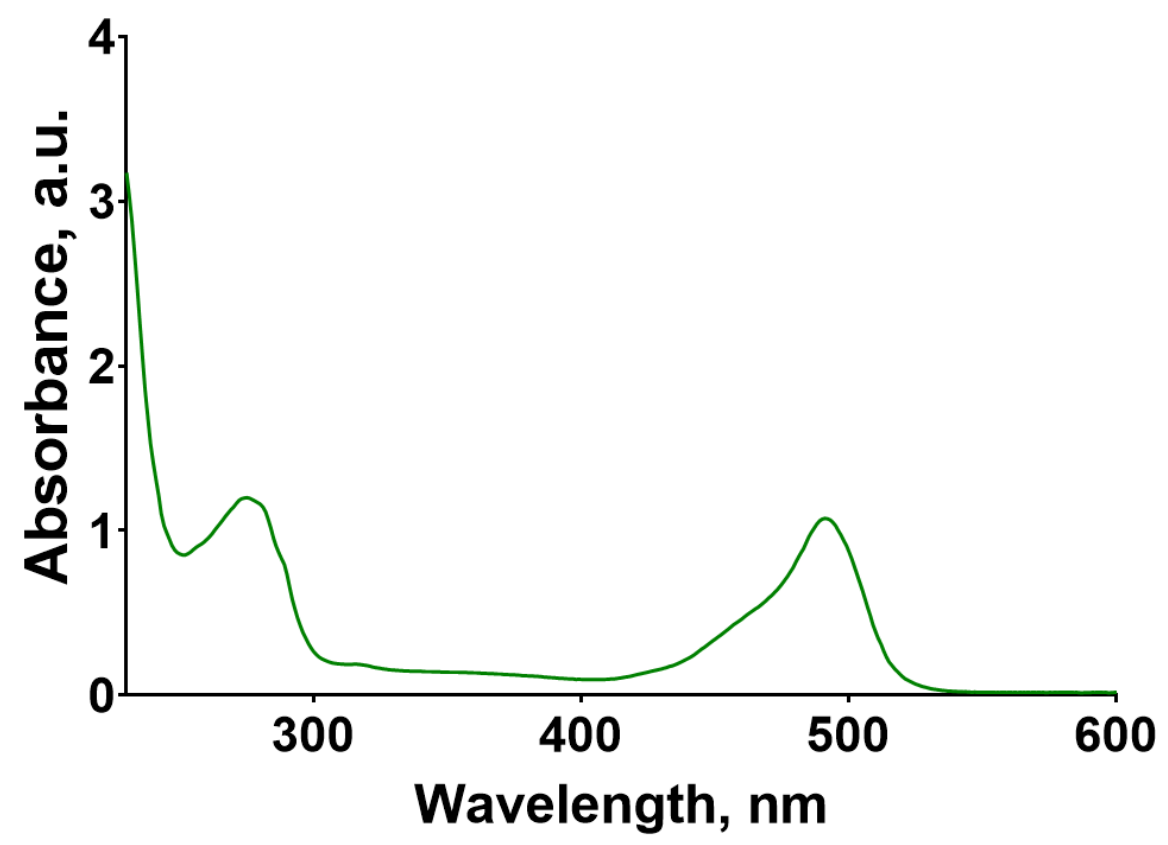

Figure S2. Absorption spectra of IgG-FITC. 


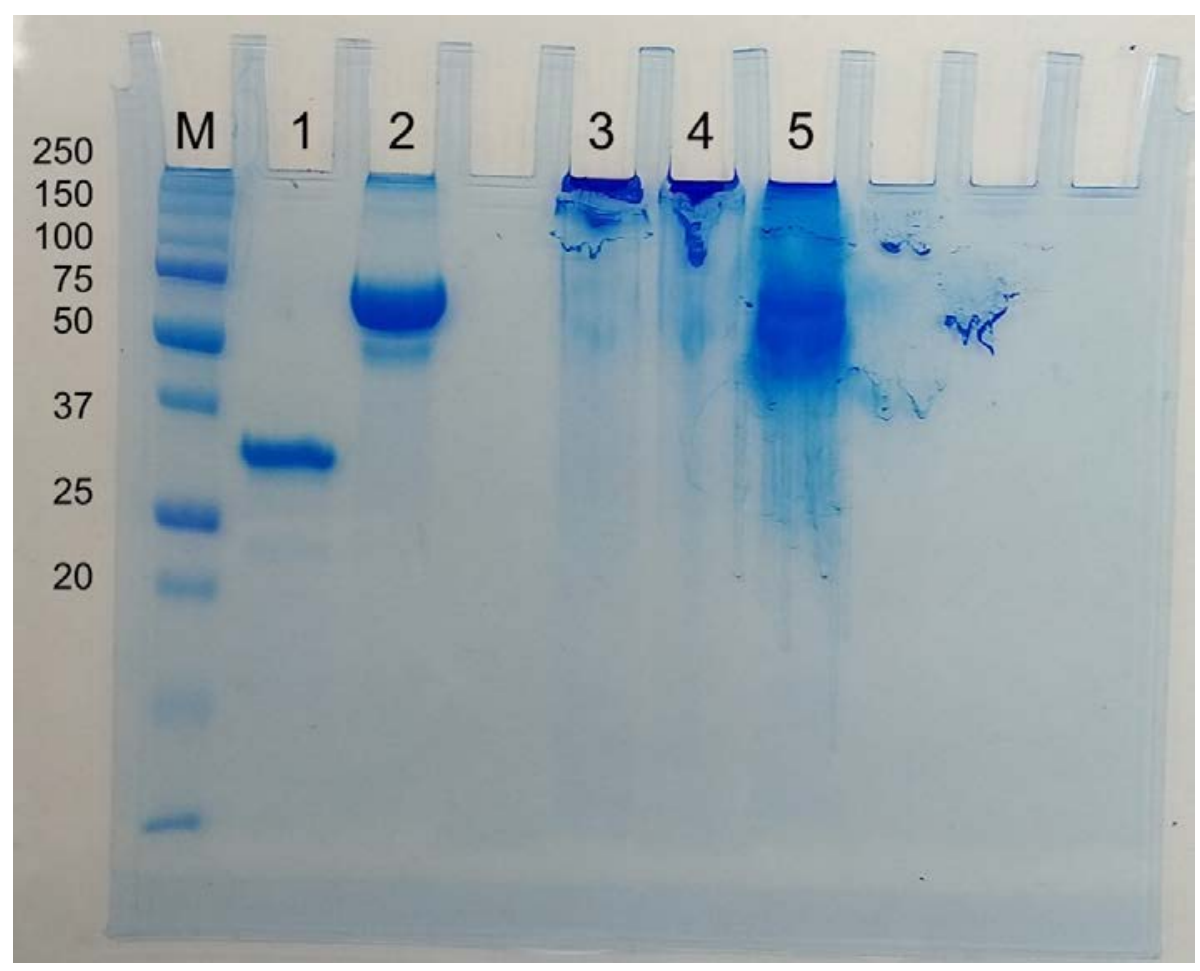

Figure S3. SDS-PAGE of protein G, BSA, and undiluted BSA/hemin nanoparticles with beta-mercaptoethanol and heating at $+95^{\circ} \mathrm{C}$ : $\mathrm{M}$ - protein markers, 1 - protein $\mathrm{G}$ (1 $\mathrm{mg} / \mathrm{ml}), 2$ - BSA $(1 \mathrm{mg} / \mathrm{ml}), 3$ - NP5 $(5.1 \mathrm{mg} / \mathrm{ml}), 4$ - NP10 $(11.7 \mathrm{mg} / \mathrm{ml}), 5$ - NPC $(5.4$ $\mathrm{mg} / \mathrm{ml})$.

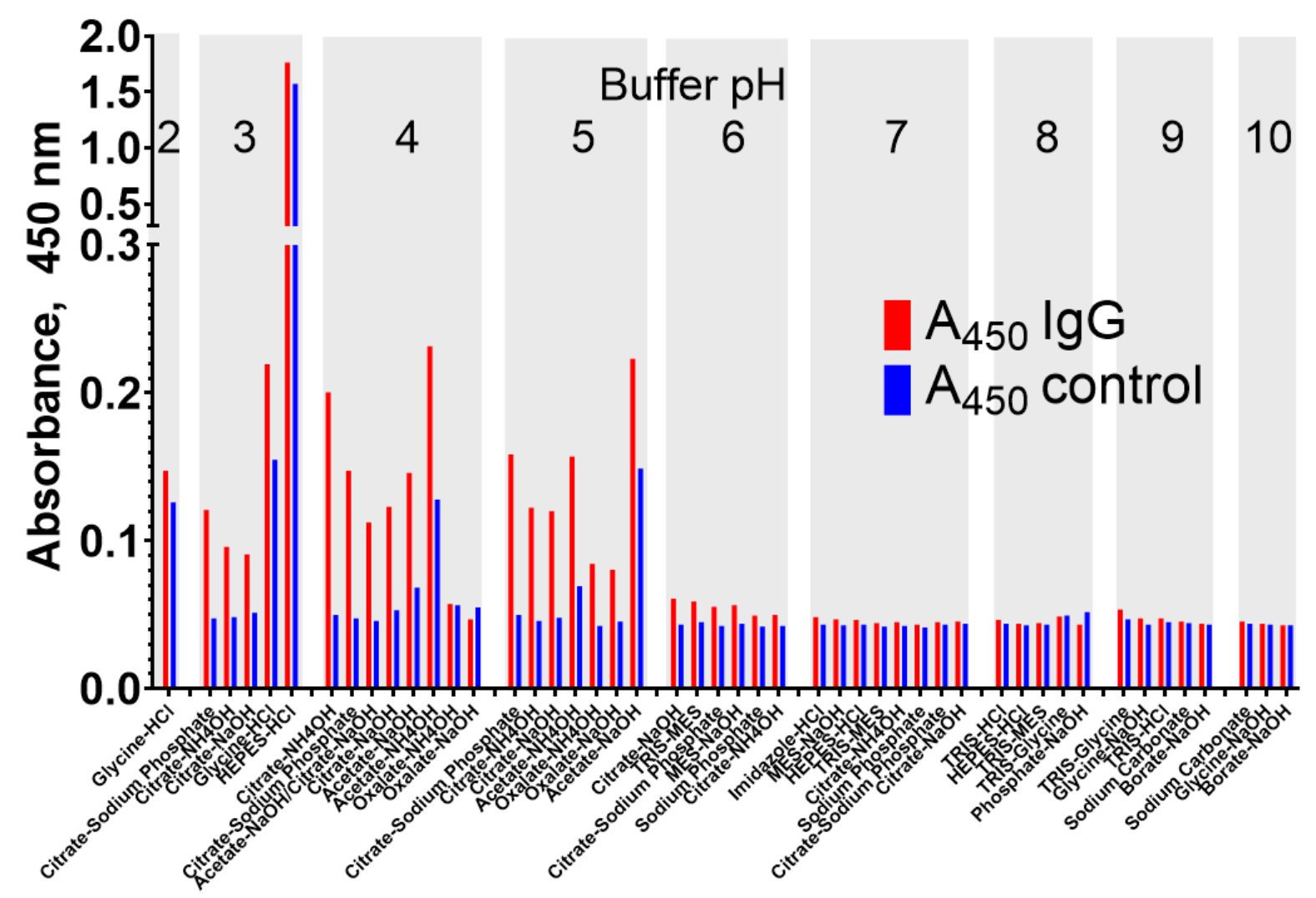

Figure S4. Optimization of substrate buffers. Absorbance at $450 \mathrm{~nm}$ measured in empty wells and in wells coated with IgG. 


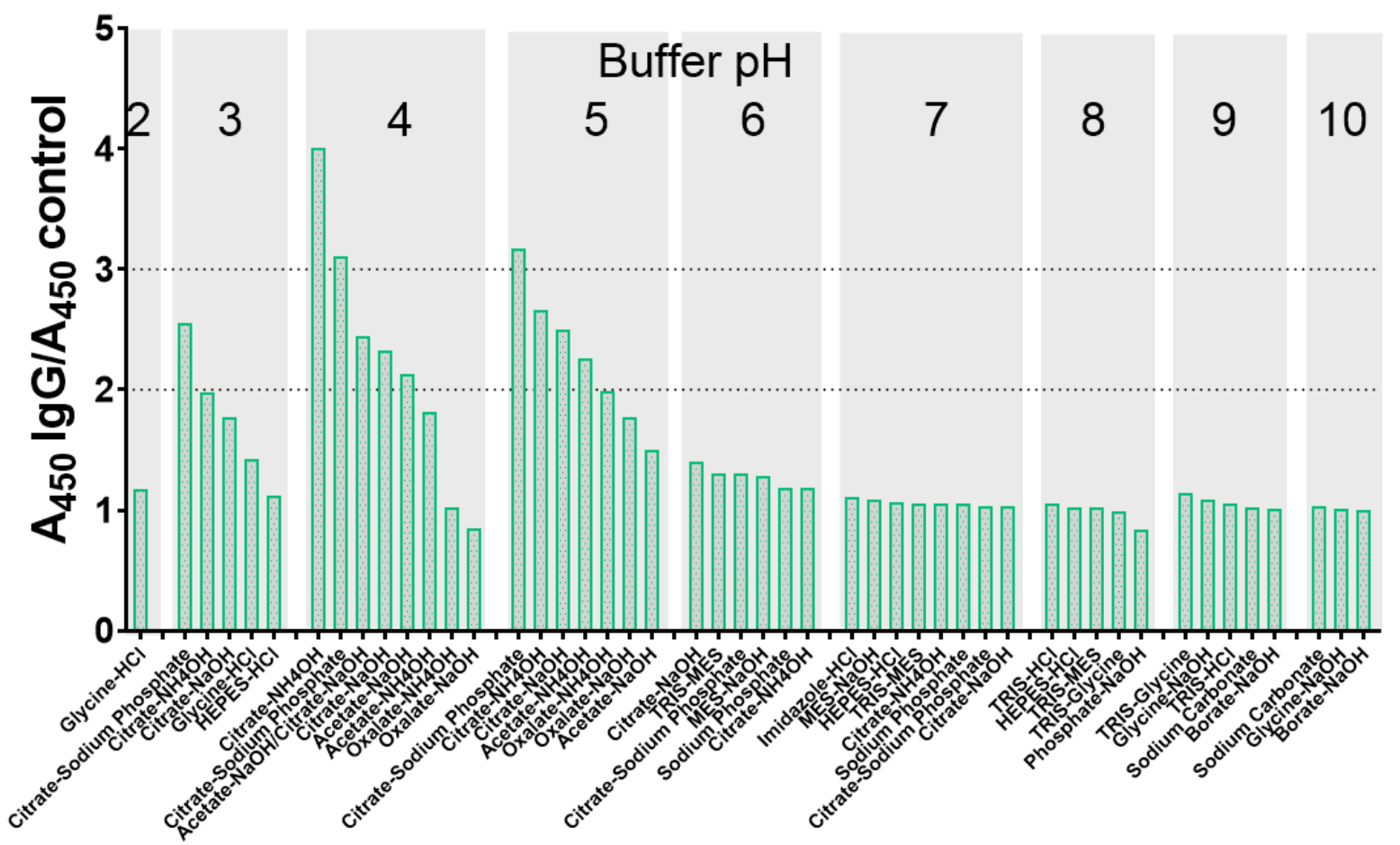

Figure S5. Optimization of substrate buffers. Ratios of absorbance at 450 in IgG-coated wells to that of empty wells (see Figure S4)
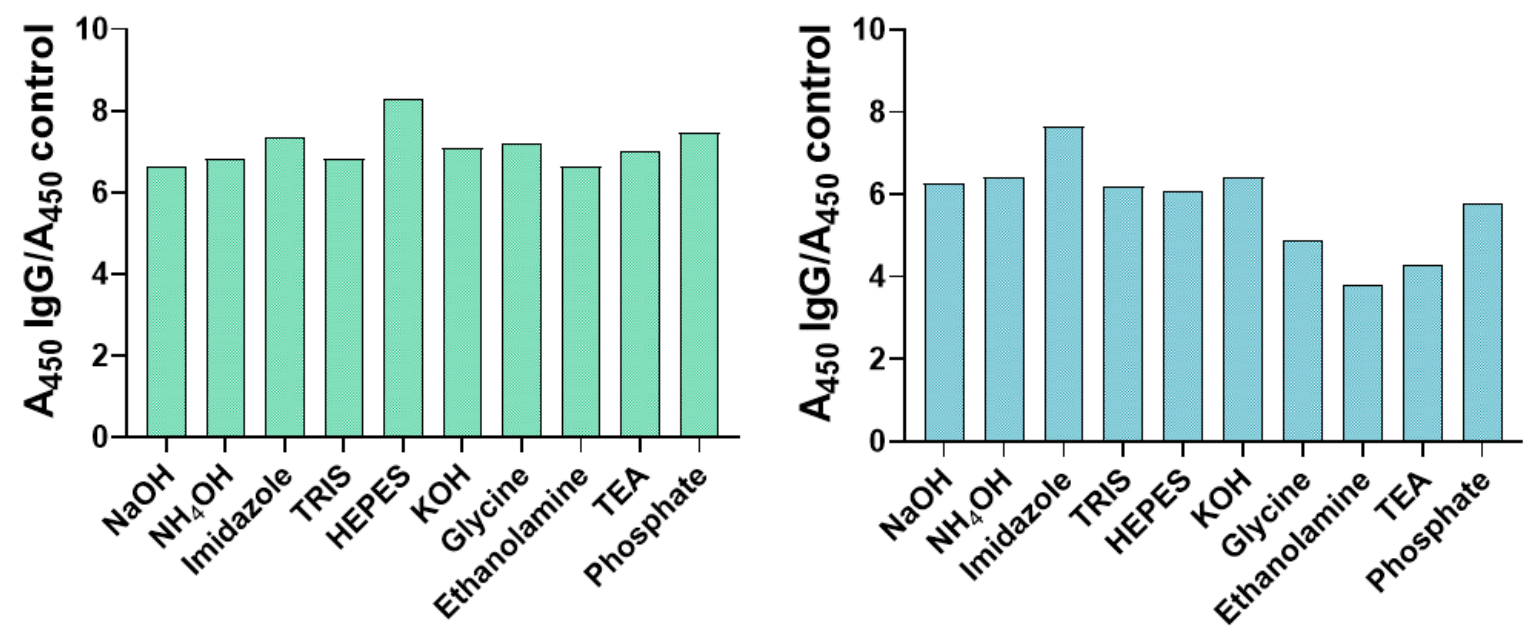

Figure S6. Ratios of A450 of positive (10 $\mu \mathrm{g} / \mathrm{ml}$ of $\mathrm{IgG})$ and blank samples obtained with different citrate-based buffers: $\mathrm{pH} 4(\mathrm{~A})$ and $\mathrm{pH} 5$ (B). TEA - triethylamine. See Figure 7 for details 